\title{
FLORÍSTICA E FITOSSOCIOLOGIA DE UMA ÁREA DE VEGETAÇÃO CILIAR RESTAURADA NO PONTAL DO PARANAPANEMA, SÃO PAULO
}

\author{
FLORISTIC AND PHYTOSOCIOLOGICAL ANALYSIS IN \\ A RESTORED AREA OF RIPARIAN FORESTS IN \\ PONTAL DO PARANAPANEMA, SÃO PAULO'STATE
}

\section{Elisangela Ronconi Rodrigues ${ }^{1}$, Reinaldo Monteiro', Laury Cullen Junior ${ }^{2}$, Tiago Pavan Beltrame ${ }^{2}$, Antonio Vicente Moscogliato ${ }^{2}$}

${ }^{1}$ Depto de Botânica, UNESP, Rio Claro. Av. 24-A, 1515, Rio Claro-SP. e-mail: elisronconi@gmail.com

${ }^{2}$ IPE - Instituto de Pesquisas Ecológicas. Rua Ricardo Fogarolli, 387, Teodoro Sampaio, SP. e-mail: lcullen@stetnet.com

\section{RESUMO}

O Pontal do Paranapanema, extremo oeste do Estado de São Paulo, é marcado pela recente devastação florestal, e ações que visam à recuperação de áreas onde outrora havia cobertura florestal tornam-se indispensáveis para a conservação da biodiversidade na região, principalmente quando se trata de Áreas de Preservação Permanente. Diante do exposto, esta pesquisa teve como objetivo realizar um levantamento florístico e fitossociológico em uma área de 81 hectares de preservação permanente, restaurada pelo método de parcelas. Os resultados mostraram a presença de 55 espécies distribuídas em 23 famílias botânicas. Apesar do número de espécies estar abaixo do recomendado pela legislação competente, as espécies presentes na área são adequadas a uma área de influência ripária do bioma Floresta Estacional Semidecidual, o que garante o início do desenvolvimento do plantio e serve como base para desencadear o processo de sucessão secundária na área.

Palavras-chaves: Mata ciliar. Fitossociologia. Restauração.

\begin{abstract}
The Pontal do Paranapanema, region located in the western range of the São Paulo'State is characterized by recent forest destruction, and actions are needed for forest restorations and landscape conservation for the biodiversity conservation in the region. Thus, this research had the objective to carry a floristic and phytosociological analysis in 81 hectares of restored area of permanent preservation, by the parcels method. The results showed the presence of 55 species distributed in 23 botanical families. Despite the planted species number be lower than the
\end{abstract}


recommended by legislation, the species presented are charicterized by the Bioma Semideciduous Seasonal Forest, and could represent the basis for natural forest succession in the area.

Keywords: Riparian forests. Phytosociological analysis. Restoration.

\section{INTRODUÇÃO}

A recuperação de sítios degradados não é um processo simples. Após sofrer um distúrbio, um sítio degradado perde, juntamente com a sua vegetação, os seus meios bióticos de regeneração, impedindo, assim, o retorno natural do ecossistema à sua condição inicial. Nesses casos, é necessária uma forte intervenção antrópica para que sejam superados impedimentos existentes à recuperação natural do ecossistema, possibilitando o retorno da área à condição pré-existente ou a algum estado estável permanente (ANAND e DESROCHERS, 2000; RODRIGUES e GANDOLFI, 2000).

No Brasil, as áreas de vegetação ripária encontram-se entre as mais fortemente afetadas, estando, na sua grande maioria, em estado degradado. Segundo Martins (2001), além da destruição pelo processo de urbanização, as matas ciliares sofrem pressão antrópica por uma série de outros fatores: são as áreas diretamente mais afetadas na construção de hidrelétricas; nas regiões com topografia acidentada, são as áreas preferenciais para a abertura de estradas, para a implantação de culturas agrícolas e de pastagens e, para os pecuaristas, representam obstáculos de acesso do gado ao curso d'água. Frequentemente, também são perturbadas por desmatamentos, grandes queimadas, mineração e retirada de terra para os mais diversos fins (REZENDE, 1998).

De acordo com um levantamento realizado pela Secretaria Estadual de Meio Ambiente, no Estado de São Paulo há 3,4 milhões de hectares cobertos por vegetação nativa, o que corresponde a apenas $13,7 \%$ de sua área total. A maior parte deste percentual está concentrada nas áreas de declive acentuado da Serra do Mar e em unidades de conservação administradas pelo poder público. (SMA, 2002).

A importância da cobertura vegetal ao redor de rios, lagos e reservatórios fundamenta-se nos benefícios que este tipo de vegetação acarreta ao equilíbrio do ecossistema como um todo, exercendo função protetora para seus componentes bióticos e abióticos (DURIGAN e SILVEIRA, 1999). Como são fundamentais para o equilíbrio ambiental, recuperá-las pode significar benefícios muito significativos sob vários aspectos. Em escala local e regional, protegem a água e o solo, oferecem abrigo e sustento à fauna e funcionam como barreira reduzindo a propagação de pragas e doenças nas culturas agrícolas. Em escala global, as florestas em crescimento fixam carbono e contribuem para a redução dos gases de efeito estufa (SMA, 2002).

Isso torna claro que essa vegetação merece atenção e incentivo governamental para ações que visem à restauração de áreas onde deveria haver vegetação ciliar. Apesar da legislação brasileira determinar sua preservação a quatro décadas, de acordo com o Código Florestal (Lei Federal 4771 de 15 de setembro de 1965), muito pouco se tem feito nesse sentido e as áreas desmatadas são maiores do que as áreas restauradas. De acordo com BARBOSA (2006), estima-se que cerca de 1,3 milhões de hectares de áreas marginais aos cursos d'água estejam sem cobertura vegetal no Estado de São Paulo.

Esta drástica redução das matas ciliares, bem como a fragmentação das florestas em geral, verificadas nos últimos anos no Brasil, tem causado aumento significativo dos processos de erosão dos solos, com prejuízos à hidrologia regional, evidente redução da biodiversidade e a degradação de imensas áreas (MELO e DURIGAN, 2007).

Existem diferentes propostas metodológicas que visam à recuperação ou a restauração de áreas degradadas, assim como existe muita discussão sobre a utilização desses dois termos. 
Atualmente, o plantio de mudas tem sido o método mais utilizado em projetos de restauração (FERREIRA et al., 2007)

Entretanto, o processo de recuperação de áreas de matas ciliares depende de vários fatores, dentre os quais se destacam: o grau de modificação em relação ao ambiente natural, as espécies a serem utilizadas, a obtenção de propágulos, a distribuição dessas espécies no novo ambiente e a participação de comunidade humana (FERREIRA et al., 2007).

É indiscutível a importância de se manter ou recuperar a cobertura florestal junto aos corpos d'água. O desafio está, no entanto, em encontrar técnicas adequadas de revegetação e superar as barreiras culturais e sócio-econômicas que impedem que se promova a recuperação de matas ciliares em larga escala (DURIGAN e SILVEIRA, 1999).

Por fim, o monitoramento e a avaliação dos projetos com essa finalidade tornam-se fundamentais para o avanço do conhecimento científico-tecnológico, o que subsidiará novas propostas e norteará a tomada de decisões. Neste sentido, um levantamento fitossociológico na fase inicial do projeto é uma importante ferramenta para monitoramentos em longo prazo, permitindo acompanhar não só o desenvolvimento da comunidade implantada como sua sucessão e estabelecimento ao longo do tempo.

Diante do exposto, este pesquisa teve como objetivo realizar um levantamento fitossociológico em uma área restaurada de vegetação ciliar localizada as margens do Ribeirão do Evaristo, região do Pontal do Paranapanema.

\section{METODOLOGIA}

\subsection{Caracterização da Área de Estudo}

O Pontal do Paranapanema localiza-se no extremo Oeste de São Paulo, entre as confluências dos Rios Paraná e Paranapanema, é a segunda região mais pobre do Estado, marcada pela recente e voraz devastação florestal, intensificada a partir da década de 1950, que transformou a paisagem da região em extensas áreas de monocultivos e pastagens (VALLADARES-PADUA et al., 2002).

A vegetação característica da região é classificada como Floresta Estacional Semidecidual, inserida nos domínios da Mata Atlântica, sendo por isso popularmente chamada de "Mata Atlântica do Interior". Ela está predominantemente fixada sobre latossolo vermelho, derivado de rochas sedimentares, formadas principalmente por arenito-caiuá resultante da compactação da areia (ATLAS INTERATIVO DO PONTAL DO PARANAPANEMA, 2001).

No que tange aos aspectos climatológicos, a região caracteriza-se, segundo a classificação de Köeppen, pelo tipo CWA - mesotérmico, de inverno seco, caracterizado por temperaturas médias anuais ligeiramente inferiores a $22{ }^{\circ} \mathrm{C}$, com chuvas típicas de clima tropical (LEITE, 1998). A precipitação é marcadamente maior de outubro a abril, sendo o período mais chuvoso de dezembro a fevereiro, tanto em freqüência quanto em volume; de maio a setembro as chuvas reduzem-se sensivelmente. O período de maiores índices pluviométricos predispõe mais os agroecossistemas ao processo de erosão, principalmente nos meses de outubro, novembro e dezembro, quando o solo está na fase de preparo para o cultivo (ITESP, 1999).

Dentro desse mosaico formado por uma matriz de assentamentos e poucos remanescentes florestais, a área de estudo abrangida por esta pesquisa consiste em uma faixa de vegetação ciliar degradada, cuja recuperação teve início em junho de 2006 pela Organização Não Governamental IPE - Instituto de Pesquisas Ecológicas, pelo método de plantio de mudas. As mudas provenientes para a recuperação dessa área foram adquiridas pelo viveiro da CESP - Companhia Energética de São Paulo. O espaçamento do plantio é de $4 \mathrm{~m} \times 3 \mathrm{~m}$ e as espécies utilizadas foram selecionadas tendo como critério: a ocorrência em área ripária na região, o grupo sucessional e a disponibilidade 
do viveiro. O total de área restaurada é 81 hectares, localizada as margens do Ribeirão do Evaristo, que se localiza entre os municípios de Teodoro Sampaio e Euclides da Cunha Paulista.

\subsection{Delineamento Experimental}

Foram instaladas na área 20 parcelas de $30 \mathrm{~m} \mathrm{X} 15 \mathrm{~m}$ com amostragem de todos os indivíduos arbóreos presentes dentro das parcelas. Alguns parâmetros fitossociológicos comumente utilizados para análises de comunidades florestais foram calculados (DURIGAN e LEITÃOFILHO, 1995), com o uso do software FITOPAC (SHEPHERD, 1988), sendo eles: Freqüência absoluta (FA), Densidade absoluta (DA), Dominância absoluta (DoA), Freqüência relativa (FR), Densidade relativa (DR), Dominância relativa (DoR), Valor de importância (VI) e Valor de cobertura (VC).

A heterogeneidade florística do sítio de amostragem foi calculada pelo índice de diversidade de Shannon, (PIELOU, 1984) e a similaridade florística analisada através do índice de Jaccard (MÜLLER-DOMBOIS e ELLENBERG, 1974), comparando-se o plantio com o levantamento realizado por Baitello et. al. (1988) e Souza e Batista (2004), ambos os trabalhos realizados na região do Pontal do Paranapanema.

A classificação do grupo ecológico das espécies foi feita por meio de consulta bibliográfica (CARDOSO-LEITE, 2004; CARVALHO, 2003; SILVA et.al. 2003; PAULA et.al. 2002; SOUZA e BATISTA, 2004; LORENZI, 1998; LORENZI, 1992) tendo como base a classificação sugerida por Budowski (1965) que identifica quatro grupos ecológicos funcionais: pioneiras, secundárias iniciais, secundárias tardias e climácicas.

\section{RESULTADOS E DISCUSSÃO}

$\mathrm{Na}$ área de vegetação ripária restaurada foram amostrados 1.531 indivíduos distribuídos em 55 espécies e 23 famílias botânicas, resultando em uma densidade total de 1964,44 indivíduos/ha e a área basal total foi de $0,214 \mathrm{~m}^{2} /$ ha. A mortalidade na área foi de $13,40 \%$ durante o período de 1 ano. Os demais indicadores fitossociológicos encontram-se na Tabela 1.

As famílias com maior número de espécies foram: Mimosaceae (9 espécies); Bignoniaceae (6 espécies); Euphorbiaceae (4 espécies); Myrtaceae (4 espécies) e Caesalpiniaceae (4 espécies), Boraginaceae ( 3 espécies); Anacardiaceae ( 3 espécies) Moraceae (3 espécies). Essas oito famílias juntas reúnem $64,28 \%$ do total de espécies amostradas na área.

Santos e Kinoshita (2003) também encontraram poucas famílias agrupando a maioria das espécies em um levantamento de vegetação riparia em bioma de floresta estacional semidecidual no estado de São Paulo. Segundo os autores, esta característica é comum em levantamentos florísticos realizados neste bioma.

Leitão Filho et al. (1998) analisaram 19 estudos fitossociológicos e compilaram75 famílias e 569 espécies presentes em áreas de floresta estacional semidecidual no estado de São Paulo, mostrando a grande riqueza e diversidade existente neste tipo florestal.Os mesmo autores citam as famílias Myrtaceae, Euphorbiaceae, Fabaceae (presentes neste estudo), Rubiaceae e Lauraceae, como caracteristicamente abundantes nas matas do interior do estado de São Paulo.

Em relação ao Valor de Importância (VI), as dez famílias encontradas (em ordem decrescente) foram Euphorbiaceae, Ulmaceae, Sterculiaceae, Mimosaceae, Cecropiaceae, Rhamnaceae, Boraginaceae, Anacardiaceae, Bignoniaceae e Moraceae. Para espécies, as dez com maior VI foram Croton urucurana, Croton floribundus, Trema micrantha, Guazuma ulmifolia, Cecropia pachystachya, Hovenia dulcis, Cordia superba, Inga uruguensis, Colubrina glandulosa e Schinus terebinthifolius. 
Com exceção de Croton floribundus, Trema micrantha, Hovenia dulcis e Inga uruguensis, todas as espécies supracitadas constam na listagem de espécies arbóreas recomendadas para plantios de matas ciliares no oeste paulista, conforme Durigan et al. (2003).

Melo e Durigan (2007), em um estudo conduzido em nove áreas de restauração de vegetação ciliar no oeste paulista encontrou as espécies M. urundeuva, E. contortisiliquum e G. ulmifolia plantadas em 77,8\% dos reflorestamentos. Em seguida, aparecem as espécies $S$. terebinthifolius, $T$. avellanedae, C. urucurana, C. estrellensis, $P$. rigida, $P$. guajava e $C$. Myrianthum, presentes em $66,7 \%$ dos reflorestamentos. Com exceção de C. estrellensis e T. avellanedae, as demais espécies citadas foram encontradas no levantamento feito na mata ciliar do Ribeirão do Evaristo.

De acordo com Barbosa (2000), a base para a restauração e estabelecimento de comunidades vegetais deve ser a utilização de espécies nativas, pois estas são fundamentais na integração e manutenção da biodiversidade, na estrutura dos ecossistemas e nas interações com a fauna, além de apresentarem funções relacionadas com conservação hidrológica e geológica.

Entretanto, pode-se observar no levantamento realizado, a presença da espécie exótica Hovenia dulcis, popularmente chamada de "Uva do Japão", constando, inclusive, entre as dez espécies com maior VI, o que futuramente pode levar a um comprometimento das espécies nativas, visto que $H$. dulcis é considerada espécie invasora, que compete por espaço, luz e nutrientes com espécies nativas, reduzindo a disponibilidade destes recursos para estas últimas, bem como diminui a quantidade de fauna polinizadora e dispersora de sementes para as espécies nativas (INSTITUTO HORUS, 2007). Em longo prazo, este processo pode levar a uma diminuição da quantidade de espécies nativas da floresta a ponto de haver uma homogeneidade da flora, com predominância da espécie invasora. A agressividade competitiva de $H$. dulcis se justifica principalmente, pelo vigor de germinação de suas sementes e sua capacidade de formação de banco de sementes no solo (INSTITUTO HORUS, 2007).

Apesar do exposto, a presença desta espécie exótica também se fez presente no levantamento florístico da parte restaurada de vegetação ciliar realizado por Veiga et al. (2003) bem como em diversos levantamentos realizados em remanescentes florestais, como é o caso de Bardall et al. (2003); Cardoso-Leite (2004); Seger et. al. (2005); Souza et al. (2005), demonstrando a ampla ocorrência invasiva da espécie.

O índice de diversidade de Shannon (H') obtido neste levantamento foi de 3,05 para espécies. Comparou-se o valor encontrado para espécie nesta pesquisa com outros levantamentos realizados em vegetação riparia característica de Floresta Estacional Semidecidual, onde Teixeira e Rodrigues (2006) obtiveram H' =3,17; Cardoso-Leite (2004) obteve $\mathrm{H}^{\prime}=3,08$; Veiga et. al. (2003) obteve H' = 2,54; Toledo-Filho (2000) encontrou H' $=3,73$; enquanto Durigan e Leitão-Filho (1995) obtiveram $H^{\prime}=2,93$. Desta maneira, o valor encontrado nesta pesquisa não se mostra inferior ao encontrado em áreas de remanescentes florestais.

Isto remete à idéia de que o plantio realizado na área possui valores adequados de espécies. Entretanto, encontram-se abaixo do recomendado pela Resolução 8 da Secretaria do Meio Ambiente do Estado de São Paulo de 31/01/2008, que determina um mínimo de 80 espécies para projetos acima de 1 hectare (SMA, 2008). Também o número de espécies está muito aquém do que é encontrado no ambiente natural. Os levantamentos realizados no Parque Estadual Morro do Diabo por Baitello et al. (1988) amostrou 120 espécies distribuídas em 44 famílias botânicas, enquanto Schlittler et al. (1995) amostraram 111 espécies distribuídas em 42 famílias botânicas. Esta maior riqueza observada no Parque pode ser explicada pela presença de um grande número de espécies ocorrendo em baixas densidades, característica comum das Florestas Tropicais (HARTSHORN, 1980).

Salis et al. (1995), com base num grande número de levantamentos florísticos já realizados, evidenciaram que há uma regionalização da flora nas florestas do interior do Estado de São Paulo. Assim, compararam-se as famílias e espécies encontradas neste levantamento com o estudo 
fitossociológico conduzido no Parque Estadual Morro do Diabo por Baitello et al. (1988), em uma área de influência ripária antes de seu alagamento pela usina Hidroelétrica de Porto Primavera e com o estudo conduzido por Souza e Batista (2004) em áreas restauradas ao redor dos lagos das usinas de Porto Primavera e Taquaruçu, ambos localizados na região do Pontal do Paranapanema.

Conforme a equação de Jaccard (MÜLLER-DOMBOIS e ELLENBERG, 1974), o índice de similaridade obtido para famílias foi de 39,58\% quando comparado a Baitello et. al. (1988) e de $45,71 \%$ quando comparado com Souza e Batista (2004). Assim, as famílias presentes na área de restauração da APP do Ribeirão do Evaristo, são aqui consideradas como representativas de uma mata ripária do bioma Floresta Estacional Semidecidual. Vale ressaltar que as famílias levantadas nesse estudo são de ampla ocorrência e não exclusivas de ambientes ripários, podendo ser encontradas também em outras formações.

Já a análise de similaridade florística para espécies obteve índice de similaridade de 13,63\% na comparação com Baitello et al. (1988) e 32,58\% quando comparado a Souza e Batista (2004). Müller-Dumbois e Ellenberg (1974) afirmam que remanescentes de mata podem ser considerados semelhantes sempre que apresentarem pelo menos $25 \%$ de concordância florística. Sendo assim, pode-se afirmar que a área de levantamento desta pesquisa não é semelhante a uma área de ocorrência de vegetação natural, mas está muito próxima de outras áreas restauradas na região.

Souza e Batista (2004) afirmam que o baixo número de espécies em áreas reflorestadas, justificável pelas dificuldades operacionais, pode ser um fator de comprometimento da diversidade da floresta passados alguns anos após o plantio, caso não haja uma colonização razoável por outras espécies. Para tal, a proximidade com possíveis "fontes" (sementes e seus agentes dispersores) é de extrema importância para que novas espécies possam colonizar tais áreas. Viana e Pinheiro (1998) complementam que o isolamento de fragmentos florestais afeta os fluxos gênicos das populações, que podem ter sua perpetuação comprometida.

A área implantada possui próximos o Parque Estadual Morro do Diabo e pequenos fragmentos que estão distribuídos pela região. Isto não constitui, portanto, um empecilho para que novas espécies colonizem futuramente a área, fator que pode ser decisivo para o sucesso deste plantio. No entanto, esta condição não é única: também é preciso avaliar se a área irá garantir seus processos ecológicos mínimos, como polinização, dispersão, regeneração natural e predação natural, fatores essenciais que poderão dizer se a área reflorestada será capaz de se regenerar e abrigar a fauna como uma floresta natural (SOUZA e BATISTA, 2004).

Também o processo de sucessão florestal deve ser considerado, uma vez que este processo se caracteriza principalmente por uma substituição gradativa de espécies no tempo, de acordo com as diferentes condições ambientais que vão se estabelecendo, às quais as espécies se adaptam (KAGEYAMA e CASTRO, 1989; LEITÃO FILHO et al., 1998).

No plantio aqui pesquisado, 39 espécies pertencem ao grupo das pioneiras, sendo 22 pioneiras $(40 \%)$ e 17 secundárias iniciais (30,90\%); 14 espécies pertencem ao grupo das não pioneiras, sendo $10(18,18 \%)$ secundárias tardias e 4 (7,27\%) climácicas. Duas espécies $(3,63 \%)$ não foram classificadas por falta de informações sobre suas características ecológicas (Tabela 1).

De acordo com Kageyama e Gandara (2000), o uso de espécies pioneiras em plantios para fins de restauração cria condições de sombreamento para as espécies dos estágios posteriores de sucessão. O uso de um modelo sucessional na implantação de florestas mistas é a tentativa de dar à regeneração artificial condições semelhantes ao que aconteceria no ambiente naturalmente, onde as espécies pioneiras são a chave que desencadearia as condições adequadas para o desenvolvimento das espécies não-pioneiras.

Entretanto, uma proporção muito elevada de espécies dos estágios iniciais de sucessão pode comprometer os processos ecológicos futuros na área. Kageyama e Gandara (2000) citam uma proporção de $60 \%$ de espécies pioneiras e $40 \%$ de espécies não pioneiras, destacando que o grupo de espécies pioneiras inclui também as secundárias iniciais e o grupo de não pioneiras inclui as 
secundárias tardias e climácicas. Dentro desta porcentagem do grupo das não pioneiras, $20 \%$ deve ser destinado ao uso de espécies raras (ou seja, aquelas que ocorrem em baixa densidade e freqüência nos levantamentos fitossociológicos) e $80 \%$ de espécies comuns. Os autores afirmam ainda que, essas características de abundância e raridade das espécies florestais são evolutivas e devem ser, portanto, incorporadas aos modelos de restauração. Já a resolução SMA-SP 8/2008 afirma que nenhum dos grupos ecológicos (pioneiras e não pioneiras) pode exceder $60 \%$ do total dos indivíduos do plantio.

Estas recomendações visam aproximar as condições de plantio ao que ocorre no ambiente natural. Entretanto, Ivanauskas et. al. (1999) obtiveram, em um levantamento realizado em uma área de Floresta Estacional Semidecidual, no município de Itatinga, SP, resultados distintos das proporções supracitadas. Dentre o total de indivíduos amostrados 5,24\% de espécies tipicamente pioneiras, 40,57\% de espécies secundárias iniciais, 33,12\% de espécies secundárias tardias, 9,64\% de espécies sem caracterização e 11,42\% de árvores mortas. Também Higuchi et al. (2006) encontraram uma menor proporção de espécies pioneiras num levantamento da regeneração espontânea de um fragmento de Floresta Estacional Semidecidual em Viçosa, atribuindo ao fechamento do dossel a explicação para o baixo número de espécies pioneiras.

Resultados mais próximos aos encontrados nesta pesquisa foram obtidos por Cardoso-Leite (2004), em um levantamento realizado em mata ciliar no município de Rio Claro-SP, onde a proporção encontrada foi de $60 \%$ pioneiras, $16 \%$ secundárias iniciais, $16 \%$ secundárias tardias e $8 \%$ climácicas.

Porém, vale ressaltar que a classificação das espécies em grupos ecológicos pode ser variável, uma vez que diferentes autores usam de critérios diferenciados, o que muitas vezes leva uma mesma espécie a ser classificada em grupos distintos. Também uma mesma espécie pode responder diferentemente, devido à sua variabilidade genética, às condições ambientais, como tipologia de solo, clima, regime hídrico (SILVA et al. (2003) ou às condições antrópicas como fogo, desmatamento, agricultura, etc (KAGEYAMA e GANDARA, 2000).

\section{CONCLUSÕES}

Os resultados desta pesquisa mostram que a área restaurada do Ribeirão do Evaristo apresenta espécies adequadas a uma área de influência ripária do bioma Floresta Estacional Semidecidual, o que garante o início do desenvolvimento do plantio e serve como base para desencadear o processo de sucessão secundária na área. O que também poderá ser favorecido devido à proximidade desta área com possíveis fontes de propágulos.

Entretanto, devido à utilização da espécie exótica $H$. dulcis e uma diversidade de espécies abaixo do recomendado pela legislação estadual para reflorestamentos ambientais, futuramente pode haver a necessidade de novas intervenções para enriquecimento da área bem como para o controle de táxons invasores.

TABELA 1 - espécies arbóreas amostradas na área de preservação permanente do Ribeirão do Evaristo, por ordem decrescente de VI (valor de importância), onde: $\mathrm{N}=$ número de indivíduos; $\mathrm{FA}$ = freqüência absoluta $(\%) ; \mathrm{DA}=$ densidade absoluta (árvores/ha); $\mathrm{DOA}=$ dominância absoluta $\left(\mathrm{m}^{2} / \mathrm{ha}\right) ; \mathrm{DR}=$ densidade relativa $(\%) ; \mathrm{FR}=$ freqüência relativa $(\%) ; \mathrm{DOR}=$ dominância relativa $(\%) ; \mathrm{VC}=$ valor de cobertura; $\mathrm{GE}=$ grupo ecológico

TABLE 1 - Arboreal species collected in the permanent preservation area in Ribeirão do Evaristo, organized in a decreasing order based on the importance value (VI), where: $\mathrm{N}=$ number of individuals; $\mathrm{FA}=$ absolute frequency (\%); DA = absolute density (trees/ha); DOA = absolute dominance $\left(\mathrm{m}^{2} / \mathrm{ha}\right) ; \mathrm{DR}=$ relative density $(\%) ; \mathrm{FR}=$ relative frequency $(\%) ; \mathrm{DOR}=$ relative dominance $(\%) ; \mathrm{VC}=$ covering value; $\mathrm{GE}=$ ecological group. 


\begin{tabular}{|c|c|c|c|c|c|c|c|c|c|c|}
\hline ESPÉCIE & $N$ & $F A$ & $D A$ & DoA & $D R$ & DoR & $F R$ & $\boldsymbol{V I}$ & $V C$ & GE \\
\hline Croton urucurana Baill. & 204 & 100 & 226,7 & 0,0748 & 11,54 & 31,39 & 4,14 & 47,07 & 42,93 & $\mathrm{P}$ \\
\hline Croton floribundus Spreng. & 169 & 100 & 187,8 & 0,0486 & 9,56 & 20,41 & 4,14 & 34,11 & 29,97 & $\mathrm{P}$ \\
\hline Trema micrantha (L.) Blume & 103 & 100 & 114,4 & 0,0547 & 5,83 & 22,95 & 4,14 & 32,92 & 28,78 & $\mathrm{P}$ \\
\hline Guazuma ulmifolia Lam & 276 & 100 & 306,7 & 0,0271 & 15,61 & 11,37 & 4,14 & 31,12 & 26,98 & $\mathrm{P}$ \\
\hline Cecropia pachystachya Trec. & 96 & 100 & 106,7 & 0,0088 & 5,43 & 3,70 & 4,14 & 13,27 & 9,13 & $\mathrm{P}$ \\
\hline Hovenia dulcis Thunb. & 80 & 100 & 88,9 & 0,0021 & 4,52 & 0,89 & 4,14 & 9,56 & 5,41 & $\mathrm{P}$ \\
\hline Cordia superba Cham. & 58 & 85 & 64,4 & 0,0048 & 3,28 & 2,02 & 3,52 & 8,82 & 5,30 & $\mathrm{P}$ \\
\hline Inga uruguensis Hook \& Arn. & 57 & 85 & 63,3 & 0,0022 & 3,22 & 0,91 & 3,52 & 7,65 & 4,13 & $\mathrm{P}$ \\
\hline Colubrina glandulosa Perk. & 31 & 75 & 34,4 & 0,0007 & 1,75 & 0,29 & 3,11 & 5,15 & 2,04 & SI \\
\hline Schinus terebinthifolius Raddi & 32 & 70 & 35,6 & 0,0009 & 1,81 & 0,39 & 2,90 & 5,10 & 2,20 & $\mathrm{P}$ \\
\hline Triplaris brasiliana Cham. & 30 & 70 & 33,3 & 0,0001 & 1,70 & 0,06 & 2,90 & 4,65 & 1,75 & SI \\
\hline Ficus insipida Willd. & 24 & 65 & 26,7 & 0,0005 & 1,36 & 0,20 & 2,69 & 4,25 & 1,55 & SI \\
\hline Chlorophora tinctoria (L.) Gaud. & 20 & 60 & 22,2 & 0,0015 & 1,13 & 0,62 & 2,48 & 4,24 & 1,76 & ST \\
\hline Jacaranda cuspidifolia Mart. & 20 & 55 & 22,2 & 0,0017 & 1,13 & 0,73 & 2,28 & 4,14 & 1,86 & $\mathrm{P}$ \\
\hline Patagonula americana $\mathrm{L}$. & 24 & 65 & 26,7 & 0,0001 & 1,36 & 0,02 & 2,69 & 4,07 & 1,38 & ST \\
\hline Astronium graveolens Jacq. & 21 & 60 & 23,3 & 0,0003 & 1,19 & 0,13 & 2,48 & 3,81 & 1,32 & SI \\
\hline Parapiptadenia rigida (Benth.) Brenan & 20 & 45 & 22,2 & 0,0019 & 1,13 & 0,79 & 1,86 & 3,79 & 1,92 & SI \\
\hline Tabebuia heptaphylla (Vell.) Toledo & 23 & 55 & 25,6 & 0,0003 & 1,30 & 0,12 & 2,28 & 3,69 & 1,42 & SI \\
\hline Anadenanthera colubrina (Vell.)Brenan & 15 & 60 & 16,7 & 0,0004 & 0,85 & 0,15 & 2,48 & 3,48 & 1,00 & SI \\
\hline Enterolobium contortisiliquum (Vell.) Morong & 15 & 40 & 16,7 & 0,0023 & 0,85 & 0,95 & 1,66 & 3,45 & 1,80 & $\mathrm{P}$ \\
\hline Muracrodruon urundeuva All. & 14 & 45 & 15,6 & 0,0002 & 0,79 & 0,08 & 1,86 & 2,73 & 0,87 & ST \\
\hline Gallesia integrifólia (Spreng.) Harms & 12 & 45 & 13,3 & 0,0000 & 0,68 & 0,02 & 1,86 & 2,56 & 0,69 & SI \\
\hline Poecilanthe parviflora Benth. & 11 & 45 & 12,2 & 0,0000 & 0,62 & 0,01 & 1,86 & 2,49 & 0,63 & $\mathrm{C}$ \\
\hline Fícus guaranitica Chodat & 9 & 45 & 10,0 & 0,0003 & 0,51 & 0,11 & 1,86 & 2,48 & 0,62 & SI \\
\hline Anadenanthera macrocarpa (Benth.) Brenan & 14 & 35 & 15,6 & 0,0004 & 0,79 & 0,16 & 1,45 & 2,40 & 0,95 & SI \\
\hline Inga laurina (Sw.) Willd. & 12 & 40 & 13,3 & 0,0001 & 0,68 & 0,04 & 1,66 & 2,37 & 0,72 & SI \\
\hline Albizia hassleri (Chodat)Burkart & 11 & 40 & 12,2 & 0,0002 & 0,62 & 0,08 & 1,66 & 2,36 & 0,70 & $\mathrm{P}$ \\
\hline Zeyheria tuberculosa Vell.) Bur & 9 & 40 & 10,0 & 0,0000 & 0,51 & 0,02 & 1,66 & 2,18 & 0,53 & SI \\
\hline Eugenia uniflora L. & 8 & 35 & 8,9 & 0,0001 & 0,45 & 0,03 & 1,45 & 1,93 & 0,48 & ST \\
\hline Casearia gossypiosperma Briquet & 7 & 35 & 7,8 & 0,0001 & 0,40 & 0,03 & 1,45 & 1,88 & 0,43 & $\mathrm{P}$ \\
\hline Mabea fistulifera Mart. & 7 & 30 & 7,8 & 0,0003 & 0,40 & 0,11 & 1,24 & 1,75 & 0,51 & $\mathrm{P}$ \\
\hline Psidium guajava $\mathrm{L}$. & 7 & 30 & 7,8 & 0,0002 & 0,40 & 0,08 & 1,24 & 1,72 & 0,48 & SI \\
\hline Ruprechtia laxiflora Meisn. & 9 & 25 & 10,0 & 0,0003 & 0,51 & 0,12 & 1,04 & 1,67 & 0,63 & SI \\
\hline Senna bicapsularis (L.) Roxb. & 5 & 25 & 5,6 & 0,0002 & 0,28 & 0,10 & 1,04 & 1,42 & 0,38 & $\mathrm{P}$ \\
\hline Zantoxylum fagara (L.) Sarg & 6 & 25 & 6,7 & 0,0000 & 0,34 & 0,00 & 1,04 & 1,37 & 0,34 & $\mathrm{~N}$ \\
\hline Inga marginata Willd. & 5 & 25 & 5,6 & 0,0001 & 0,28 & 0,04 & 1,04 & 1,35 & 0,32 & $\mathrm{P}$ \\
\hline Heliocarpus americanus L. & 5 & 20 & 5,6 & 0,0006 & 0,28 & 0,24 & 0,83 & 1,35 & 0,52 & $\mathrm{P}$ \\
\hline Sapium glandulatum (Vell.) Pax & 6 & 20 & 6,7 & 0,0001 & 0,34 & 0,04 & 0,83 & 1,21 & 0,38 & $\mathrm{P}$ \\
\hline Gochnatia polymorpha (Less.) Cabrera & 5 & 15 & 5,6 & 0,0005 & 0,28 & 0,20 & 0,62 & 1,10 & 0,48 & $\mathrm{P}$ \\
\hline Cytharexyllum myrianthum Cham. & 4 & 20 & 4,4 & 0,0000 & 0,23 & 0,00 & 0,83 & 1,05 & 0,23 & $\mathrm{P}$ \\
\hline Peltophorum dubium (Spreng.) Taub & 4 & 15 & 4,4 & 0,0003 & 0,23 & 0,12 & 0,62 & 0,97 & 0,35 & SI \\
\hline Luehea candicans Mart. & 7 & 10 & 7,8 & 0,0004 & 0,40 & 0,15 & 0,41 & 0,96 & 0,54 & SI \\
\hline Tabebuia chrysotricha (Mart.) Stand. & 5 & 15 & 5,6 & 0,0001 & 0,28 & 0,03 & 0,62 & 0,93 & 0,31 & ST \\
\hline Tabebuia impetiginosa (Mart.) Standl., & 4 & 15 & 4,4 & 0,0000 & 0,23 & 0,02 & 0,62 & 0,86 & 0,24 & ST \\
\hline Tabebuia serratifolia (Vahl) Nichols. & 3 & 15 & 3,3 & 0,0001 & 0,17 & 0,06 & 0,62 & 0,85 & 0,23 & $\mathrm{C}$ \\
\hline Hymenaea stilbocarpa Hayne & 3 & 15 & 3,3 & 0,0001 & 0,17 & 0,03 & 0,62 & 0,82 & 0,20 & ST \\
\hline Schizolobium parahyba (Vell.) Blake & 3 & 15 & 3,3 & 0,0000 & 0,17 & 0,00 & 0,62 & 0,79 & 0,17 & ST \\
\hline Eugenia florida DC & 3 & 15 & 3,3 & 0,0000 & 0,17 & 0,00 & 0,62 & 0,79 & 0,17 & $\mathrm{C}$ \\
\hline Lonchocarpus muehlbergianus Hassl. & 3 & 15 & 3,3 & 0,0000 & 0,17 & 0,00 & 0,62 & 0,79 & 0,17 & ST \\
\hline Chorisia speciosa A.St.-Hil & 3 & 10 & 3,3 & 0,0000 & 0,17 & 0,00 & 0,41 & 0,58 & 0,17 & $\mathrm{P}$ \\
\hline Psidium cattleianum Sabine & 2 & 10 & 2,2 & 0,0000 & 0,11 & 0,02 & 0,41 & 0,54 & 0,13 & SI \\
\hline Acacia polyphylla DC & 2 & 10 & 2,2 & 0,0000 & 0,11 & 0,00 & 0,41 & 0,53 & 0,12 & $\mathrm{P}$ \\
\hline Cordia trichotoma (Vell.) Arráb. ex Steud. & 2 & 10 & 2,2 & 0,0000 & 0,11 & 0,00 & 0,41 & 0,53 & 0,11 & ST \\
\hline Cedrela fissilis Vell. & 2 & 10 & 2,2 & 0,0000 & 0,11 & 0,00 & 0,41 & 0,53 & 0,11 & $\mathrm{C}$ \\
\hline Pouteria ramiflora (Mart.) Radlk. & 1 & 05 & 1,1 & 0,0000 & 0,06 & 0,00 & 0,21 & 0,26 & 0,06 & $\mathrm{~N}$ \\
\hline
\end{tabular}




\section{REFERÊNCIAS}

ANAND, M.; DESROCHERS, R.E. Quantification of restoration success using complex systems concepts and models. Restoration Ecology v. 12, n.1, p. 117-123, 2000.

ATLAS INTERATIVO DO PONTAL DO PARANAPANEMA, 2001. Disponível em <www.multimidia.prudente.unesp.br/atlaspontal> Acesso em: 12 fev de 2007.

BAitello, J. B., PASTORE, J.A., AGUIAR, O.T., SÉRIO, F.C., SILVA, C.E.F. A vegetação arbórea do Parque Estadual Morro Do Diabo, município de Teodoro Sampaio, Estado de São Paulo. Acta Botânica Brasílica. v. 1, n. 2, p. 221-230, 1988.

BARBOSA, L.M. Considerações gerais e modelos de recuperação de formações ciliares In: RODRIGUES, R.R. LEITÃO FILHO, H. F. (eds), Matas ciliares. São Paulo: Edusp, 2000.

BARBOSA, L.M. Recuperação florestal de áreas degradadas no estado de São Paulo: histórico, situação atual e projeções. In: BARBOSA, L.M. Manual para recuperação de áreas degradadas do estado de São Paulo: Matas ciliares do interior paulista. São Paulo: Instituto de Botânica, 2006.

BARDDAL, M. L., RODERJAN, C.V, GALVÃO, F., CURCIO, G.R. Caracterização florística e fitossociológico de um trecho sazonalmente inundável de floresta aluvial em Araucária, PR.

Revista Ciência Florestal. v. 14, n. 2, p. 37-50, 2003

BUDOWSKI, G. Distribuition of tropical American raisforest in the light of sucessional process. Turrialba. V.15, n.1, p. 40-42, 1965.

CARDOSO-LEITE, E. Fitossociologia e caracterização sucessional de um fragmento de mata ciliar em Rio Claro/SP, como subsídio a recuperação da área. Revista do Instituto Florestal. v.16, n.1, p. 31-41, 2004.

CARVALHO, P. E. R. Espécies Arbóreas Brasileiras. Colombo: EMBRAPA-Florestas, vol 1, 2003.

DURIGAN, G.; LEITÃO FILHO, H. F. Florística e fitossociologia de matas ciliares do Oeste Paulista. Revista do Instituto Florestal. v. 7, n. 2, p. 197-239, 1995.

DURIGAN, G.; SILVEIRA, E.R. Recomposição da mata ciliar em domínio de cerrado, Assis, São Paulo. Revista Scientia Forestalis. v.56, p.135-144, 1999.

DURIGAN, G., MELO, A.C.G., MAX, J.C.M. Manual para recuperação das matas ciliares do oeste paulista. São Paulo: Instituto Florestal, 2003. $2^{\circ}$ edição.

FERREIRA, W. C., BOTELHO, S. A., DAVIDE, A. C., FARIA, J. M. R. Avaliação do crescimento do estrato arbóreo de área degradada revegetada à margem do Rio Grande, na usina hidrelétrica de Camargos, MG.. Revista Árvore, v. 31, n.1 p. 177-185, 2007.

HARTSHORN, G. S. Neotropical forest dinamics. Revista Biotrópica. v.12, p.23-30, 1980. 
HIGUCHI, P., REIS, M.G.F., REIS, G.G., PINHEIRO, A.L., SILVA, C.T., OLIVEIRA, C.H.R. Composição florística da regeneração natural de espécies arbóreas ao longo de oito anos em um fragmento de floresta estacional semidecidual em Viçosa, MG. Revista Árvore. v. 30, n. 6, p. 893204, 2006.

INSTITUTO HORUS. Código de conduta voluntário para produtores, comerciantes e usuários de plantas ornamentais, 2007. Disponível em http://www.institutohorus.org.br/pr_ccv_ornamentais.htm Consulta em 25/06/2007.

ITESP - INSTITUTO DE TERRAS DO ESTADO DE SÃO PAULO. Pontal Verde: plano de recuperação ambiental nos assentamentos do Pontal do Paranapanema Cadernos Itesp. Numero 2, $2^{\circ}$ edição. São Paulo: ITESP/Secretaria da Justiça e da Defesa da Cidadania, 1999.

IVANAUSKAS, N.M.; RODRIGUES, R.R.; NAVE, A.G. Fitossociologia de um trecho de Floresta Estacional Semidecidual em Itatinga, SP, Brasil. Scientia Forestalis. n. 56, p. 83-99, 1999.

KAGWEYAMA, P.Y.; CASTRO, C.F.A. Sucessão secundária, estrutura genética e plantações de espécies arbóreas nativas. IPEF. n.41-42, 1989.

KAGEYAMA, P. Y.; GANDARA, F.B. Recuperação de áreas ciliares. In: RODRIGUES, R. R.; LEITÃO FILHO, H. Matas ciliares: conservação e recuperação. São Paulo: USP/FAPESP, 2000. p.249-269.

LEITÃO-FILHO, H. F., RODRIGUES, R. R., SANTIN, D. A., JOLY, C.A. Vegetação Florestal Remanescente: Inventários, caracterização, manejo e recuperação nas bacias dos Rios Piracicaba e Capivari. In: Qualidade ambiental e desenvolvimento regional nas bacias do Rio Piracicaba e Capivari. Cadernos nº 7, Campinas: NEPAM, 1998.

LEITE, J. F. A ocupação do Pontal do Paranapanema. São Paulo: Hucitec, 1998.

LORENZI, H. Árvores brasileiras: manual de identificação e cultivo de plantas arbóreas nativas do Brasil. Nova Odessa: Plantarum, 1992. vol. 1.

LORENZI, H. Árvores brasileiras: manual de identificação e cultivo de plantas arbóreas nativas do Brasil. Nova Odessa: Plantarum, 1998. vol. 2.

MARTINS, S. V. Recuperação de matas ciliares. Viçosa: Aprenda Fácil/ Centro de Produções Técnicas, 2001.

MELO, A. C. G.; DURIGAN, G. Evolução estrutural de reflorestamentos de restauração de matas ciliares no Médio Vale do Paranapanema. Scientia Forestalis (IPEF), v. 73, p. 101-111, 2007.

MÜLLER-DUMBOIS, D. ; ELLENBERG, H. Aimms and methods of vegetation ecology. John Wiley \& Sons: New York, 1974.

PAULA, A., SILVA, A. F., SOUZA, A.L., SANTOS, F.A.M. Alterações florísticas ocorridas num período de quatorze anos na vegetação arbórea de uma floresta estacional semidecidual em Viçosa, MG. Revista Árvore. v.26, n.6, p.743-749, 2002. 
PIELOU, E. C. The interpretation of ecological data: a primer on classification and ordination. John Wiley \& Sons: New York, 1984

REZENDE, A. V. Importância das matas de galeria: manutenção e recuperação. In: RIBEIRO, J. F . Cerrado: matas de galeria. Planaltina: EMBRAPA-CPAC, 1998. p. 3-16.

RODRIGUES, R. R.; GANDOLFI, S. Conceitos, tendências e ações para a recuperação de florestas ciliares. In: RODRIGUES, R. R.; LEITÃO FILHO, H. Matas ciliares: conservação e recuperação. São Paulo: USP/FAPESP, 2000. p. 235-247.

SALIS, S. M., SHEPHERD, G.J., JOLY, A.C. Floristic comparison of mesophytic semideciduous forests of the interior of the State of São Paulo, Southeast Brazil. Vegetatio v. 119, p. 155-164, 1995.

SANTOS, K ; KINOSHITA, L.S. Flora arbustivo-arbórea do fragmento de flroesta estacional semidecidual do Ribeirão Cachoeira, município de Campinas, SP. Revista Acta Botanica Brasílica. v.17, n.3, p.325-341, 2003.

SCHLITTLER, F. H. M. MARINIS, G., CESAR, O. Estudos Fitossociológicos Na Floresta do Morro do Diabo (Pontal do Paranapanema,SP). Arquivos de Biologia e Tecnologia. v. 38, n.1, p. 217-234, 1995.

SEGER, C. D., DUGLOSZ, F.L., KURASZ, G. MARTINEZ, D.T., RONCONI, E., MELO, L.A.N., BITTENCOURT, S., BRAND, M.A., CARNIATTO, I., GALVÃO, F., RODERJAN, C.V. Levantamento florístico e análise fitossociológica de um remanescente de floresta ombrófila mista localizado no município de Pinhais, Paraná-Brasil. Revista Floresta. v.35, n. 2, p. 291-302, 2005.

SHEPHERD, G. J. FITOPAC 1. Manual do usuário. Departamento de Botânica. Instituto de Biologia, Universidade Estadual de Campinas, Campinas, 1988. 93 p.

SILVA, A.F., OLIVEIRA, R.V., SANTOS, N.R.L., PAULA, A. Composição florística e grupos ecológicos das espécies de um trecho de floresta semidecídua submontana da fazenda São Geraldo, Viçosa, MG. Revista Árvore. v. 27, n.3, p. 311-319, 2003.

SMA- SECRETARIA DE MEIO AMBIENTE DO ESTADO DE SÃO PAULO. Resolução 8 de 31/01/2008. Disponível em:

http://www.cetesb.sp.gov.br/licenciamentoo/legislacao/estadual/resolucoes/2008 Res SMA 08.pdf Acesso em: 11 jul de 2011.

SMA - SECRETARIA DE MEIO AMBIENTE DE SÃO PAULO. Mata ciliar: recuperações bem sucedidas. São Paulo: SMA/SP, 2002.

SOUZA, F. M.; BATISTA, J. L. F. Restoration of Seasonal Semideciduous Forests in Brazil: influence of age and restoration design on forest structure. Forest Ecology and Management, v. 191, n. 1-3, p. 185-200, 2004.

SOUZA, M.C., KITA, K.K., SLUSARSKI, S.R., TOMAZINI, V., PEREIRA, G.F., FONTANA, A.C., ZAMPAR, R. Programa de Pesquisas Ecológicas de Longa Duração: Vegetação Ripária. Universidade Estadual de Maringá, Relatório 2005. 
TEIXEIRA, A.P.; RODRIGUES, R.R. Análise florística e estrutural do componente arbustivoarbóreo de uma floresta de galeria no município de Cristais Paulista, SP, Brasil. Revista Acta Botânica Brasílica. v.20, n.4, p.803-813, 2006.

TOLEDO FILHO, D.V. Fitossociologia de um fragmento florestal à margem do Rio do Peixe, município de Lindóia (SP). Revista do Instituto Florestal. v.12, n.1, p. 37-45, 2000.

VALLADARES-PÁDUA, C., LIMA, J.F., CULLEN, L., MORATO, M.I.R. Módulos Agroflorestais na conservação de fragmentos florestais da Mata Atlântica. Revista Experiências PDA. Brasília, v. 2, p. 7-33, Jan. 2002.

VEIGA, M. P., MARTINS, S.S., SILVA, I.C., TORMENA, C.S., SILVA, O.H. Avaliação dos aspectos florísticos de uma mata ciliar no norte do estado do Paraná. Revista Acta Scientiarum. v.25, n. 2, p. 519-525, 2003.

VIANA, V.; PINHEIRO, L. A. F. V. Conservação da biodiversidade em fragmentos florestais. Série Técnica IPEF, v. 12, n. 32, p. 25-42, 1998. 